\title{
Editorial
}

\section{Drowning in childhood - an ongoing problem}

\author{
Roger W. Byard* \\ Discipline of Anatomy and Pathology, The University of Adelaide, Adelaide, SA, Australia
}

Drowning remains one of the leading causes of accidental death in the young with at-risk ages being under four, and from 10 to 18 years. In addition to immersion episodes that result in fatalities, there are approximately three times the number of children admitted to hospital following near drowning episodes. It has been estimated that $20 \%$ of these survivors may suffer brain damage with the prognosis much worse if the time of immersion exceeds 5-10 minutes. Significant immersion incidents in the young have been associated with neglect and lack of adequate supervision [1,2]. It should be noted, however, that young children are very adept at moving quickly away from supervision, with studies showing that children who have drowned in swimming pools have been missing for less than five minutes [3].

The location of drowning varies depending on the community studied, with children more likely to drown in wells in India, bathtubs in Japan, irrigation ditches in New Mexico, pools in Australia and Texas, and the sea in Denmark [4]. The site of drowning is also agedependent with the very young being at greatest risk around home swimming pools. Young children are fascinated by water and may enjoy playing at the edge of pools where they are in danger of overbalancing. Deep water and smooth sides make escape difficult. Swimming pools may also have filtration units that can entrap young children. Other dangerous situations involve large plastic buckets partially filled with water that toddlers can tip into because of their high center of gravity and poor motor skills. Bathtubs may also present a dangerous situation due to their slippery sides; the risk may be increased if there is an older sibling

\footnotetext{
*Address for correspondence: Roger W. Byard, Discipline of Anatomy and Pathology, Level 3 Medical School North Building, The University of Adelaide, Frome Road, Adelaide, SA, 5005, Australia. Tel.: +61 88303 5441; Fax: +61 88303 4408; E-mail: roger. byard@sa.gov.au.
}

in the bath, or if an infant bath seat has been used without supervision $[5,6]$.

In this issue of the journal Orlowski and Kramer have drawn attention to another significant and often overlooked phenomenon, that of visitor drowning i.e. the increased risk of drowning in youngsters who are at other people's homes [7]. The authors reviewed 100 pediatric immersion incidents where children had either died or required hospitalization. The overall mortality rate was $10 \%$ with the usual male predominance (3:2). Analysis of the site of the incidents showed that $19 \%$ of cases involved victims who were visiting away from their home environments. The danger of children drowning at other homes has certainly been recognized in the past, with two of 10 swimming pool drowning in a series of 32 infants and children less than two years of age in South Australia occurring at residences that were not the victims [3]. The increased risk in both of these studies is similar, despite the studied communities being geographically quite separate. As in Florida, pool fencing legislation in other communities unfortunately often only applies to newly constructed pools and not to existing structures. Of note, most of the drowning incidents occurred in home swimming pools, rather than in motel pools. The authors have suggested that this may imply that parents are more vigilant when staying at motels, but become more relaxed in the homes of relatives or friends.

A number of reasons may be responsible for the increased risk of fatal immersion incidents under these circumstances: pools may not be adequately enclosed if the pool is old or if children are not normally present in the yard being visited; pool gates may be left open or broken; parents and the home owners may be distracted by the social event; and visiting children may also not be used to swimming pools or cannot swim, and may be excited by the chance to explore a new 
environment. All of these factors may contribute to an increased likelihood of an immersion incident.

An adequate investigation of such cases requires a formal evaluation of the death scene to determine whether the described series of events was plausible, how access to the pool was achieved, and whether the toddler's developmental level was appropriate for such an event. A full autopsy, including a detailed external examination, will provide evidence for or against the presence of any unexplained or unusual injuries that may suggest inflicted injury. A percentage of children who have drowned may have an underlying clinically occult condition that has predisposed to the immersion event which may only be identified at autopsy [8].

While significant reductions in childhood pool deaths have occurred in areas where pool fencing has been mandated, open gates and damaged fences still provide access for curious toddlers. Childhood drowning is one of the ongoing tragedies that may occur in the home environment - made even more tragic by the completely preventable nature of the fatal event. Continued monitoring and reporting of such deaths is required so that medical professionals and the community are kept aware of the dangers of home pools, and so that specific situations, such as visitor drowning, are clearly highlighted as in the current report.

\section{References}

[1] Byard RW. Sudden death in the young. 3rd ed. Cambridge, UK: Cambridge University Press; 2010.

[2] Stevenson MR, Rimajova M, Edgecombe D, Vickery K. Childhood drowning: barriers surrounding private swimming pools. Pediatrics 2003; 111: e115-9.

[3] Byard RW, Lipsett J. Drowning deaths in toddlers and preambulatory children in South Australia. Am J Forensic Med Pathol 1999; 20: 328-32.

[4] Somers GR, Chiasson DA, Smith CR. Pediatric drowning. A 20-year review of autopsied cases: I. Demographic features. Am J Forensic Med Pathol 2005; 26: 316-9.

[5] Byard RW, de Koning C, Blackbourne B, Nadeau JM, Krous HF. Shared bathing and drowning in infants and young children. J Paediatr Child Health 2001; 37: 542-4.

[6] Byard RW, Donald T. Infant bath seats, drowning and neardrowning. J Paediatr Child Health 2004; 40: 305-7.

[7] Orlowski JP, Cramer CL. The drowning risks associated with visiting family or friends. J Pediatr Int Care 2011.

[8] Smith NM, Byard RW, Bourne AJ. Death during immersion in water in childhood. Am J Forensic Med Pathol 1991; 12: 219-21. 